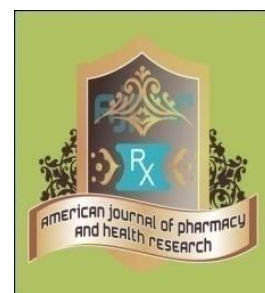

Research Article
AMERICAN JOURNAL OF PHARMACY AND HEALTH RESEARCH

www.ajphr.com

2020, Volume 8, Issue 7

ISSN: 2321-3647(online)

\title{
A Qualitative Study On Drug Waste Management Among Drug Distributors, Kochi
}

\author{
Divya Raj ${ }^{1 *}$, Densy Davis ${ }^{1}$, Githin Jose ${ }^{1}$, Kezia Joy ${ }^{2}$, Sandra Johnson ${ }^{2}$ \\ 1.Department of Pharmacy Practice, Chemists College of Pharmaceutical Sciences and \\ Research, Puthencruz, Varikoli \\ 2. Chemists College of Pharmaceutical Sciences and Research, Puthencruz, Varikoli
}

\begin{abstract}
Drug waste management has become a serious subject. Excessive use and irrational sale of medicines have led to unlimited contributions of pharmaceutical manufacturers and healthcare providers to the ground of waste production. The community pharmacies return the unused and expired drugs to the distributors who sent back these to the manufacturers. This study was initiated with an aim of identifying knowledge and behaviour of the distributers in the area of proper drug waste management. A questionnaire survey and key informant interview were used for the study. The study comprised of drug distributors from various areas of Ernakulum district. The survey conducted through face-to-face interviews using pre-validated structured questionnaire. The participants were asked about their practice, knowledge and difficulties facing on area of safe waste drug disposal. The filled questionnaire forms collected were sorted and examined for accuracy. 30 drug distributors were participated in the study and were asked to answer the questionnaire based on the drug waste management practices in their firm. Majority of them were not aware about the drug waste management and don't know any guidelines for the same. Drug waste return to them was mainly expired dosage form from retail pharmacies and also from hospital pharmacies. Most of distributors had return of drug waste in the range of 10-50 kilograms per month. The key to solve the issue of pharmaceutical waste disposal can be done in collaborative effort and co-operation between government and all the parties those who are dealing with medicines including public. Established and applied laws, along with community awareness will surely make our goal simply workable.
\end{abstract}

Keywords: Drug Waste, Distributors, Knowledge, Disposal Methods

*Corresponding Author Email: divyadominicpaul@gmail.com

Received 01 July 2020, Accepted 18 July 2020

Please cite this article as: Raj D et al., A Qualitative Study On Drug Waste Management Among Drug Distributors, Kochi. American Journal of Pharmacy \& Health Research 2020. 


\section{INTRODUCTION}

Drug waste management has become a serious issue. Even for mild headaches people used to take medication, which shows the importance of drugs is increasing in day- to -day life. Excessive use and irrational sale of medicines have led to unlimited contributions of pharmaceutical manufacturers and healthcare providers to the ground of waste production. Four to five decades ago, the focus of developed countries was how to prevent industrial and domestic waste from entering the environment. Pharmaceutical products were not recognized as environmental pollutants until the $1980 \mathrm{~s}^{1}$. But later the widespread use of pharmaceutical products in hospitals, residences and other commercial areas increased their discharge to the environment, especially to the soil and water bodies. Thus, drug waste has become an imperative part in polluting the environment.

\section{Problems Due To Improper Drug Waste Management:}

Pharmaceuticals are deposited in the environment in the form of municipal solid waste, sewage (solid, liquid) and as gaseous waste being the result of burning in the home furnace or fireplace. Burning pharmaceuticals in home furnace, release harmful substances into the air which enter either onto the ground as dry deposition, or into water, fog or snow as wet deposition. The active compounds included in pharmaceuticals are major threats to the ecosystem through their repeated accumulation, their toxic and persistent nature and the potential for such pollution to develop drugresistant microbial strains.

Unused or expired pharmaceuticals are therefore most frequently disposed of to the municipal solid waste landfill or to the sewage system. Pharmaceuticals from individual households are transported to sewage treatment plants with urban waste water. Depending on their properties, pharmaceuticals may be excreted in unchanged or changed forms as metabolites. Studies have shown that, the chemical byproducts from drug waste are causing changes in behavior, growth and reproduction of many species, specifically frogs and fishes in water bodies contaminated with drug waste have been stated by studies.

\section{Consequences of Improper Disposal of Wastes:}

Generally, Expired drugs do not pose a serious threat to the environment or other living beings but their improper disposal may lead to contamination of water supplies or other sources in contact with the wildlife. Most of the pharmaceutical drugs become less efficacious after their expiry date and few may even develop into compounds with adverse drug reaction profile. Certain antibiotics, antineoplastic as well as some disinfectants that are non-biodegradable may kill the bacteria necessary for the treatment of sewage thus they should not be disposed off into the sewage system 
or flushed in the watercourses. Usually wastes dumped in landfills leach out in aquifers, surface water or drinking water system which contaminates the aquatic systems. Toxic pollutants are released when pharmaceutical compounds or other healthcare wastes are burnt at low temperature. In some countries scavenging is hazardous in unprotected insecure landfills because expired drugs may come into the hands of scavengers and children.

\section{Methods of Disposal of Pharmaceutical Solid Wastes:}

Several treatment techniques are used widely for the drug waste management that can be expired, unused, spilled over or non-reusable. Techniques widely used include: 1.Incineration 2. Autoclaving 3. Microwaving 4. Chemical disinfection 5.Waste immobilization: encapsulation 6.Waste immobilization. But these techniques are not used by any of the health care system including drug distributors as they are not cramped within law. Drug wholesalers are the mediators between drug manufacturers and pharmacists. The unused and expired drugs are taken back from retail medical shops, dispensaries and hospitals by distributors and these drugs have to be sending back to the manufacturers. This is only way of disposing method by distributors which is not properly monitored. Since the current rules and regulation does not ask for a registered pharmacist in drug distribution or wholesale section for the handling of drugs. But in a state like Kerala were the pharmaceutical manufacturing industries are very limited, the chances for self disposal of medication by distributers are high due to transportation charges and allied problems. This study was initiated with an aim of identifying the strategies used by distributers in drug waste management.

\section{Pharmaceutical Waste Management Challenges:}

Kochi is the fast growing city in Kerala and usually household waste management is a big problem in this city. It is reported that all the waste including drug waste were given to the corporation waste collectors and deposited in the Brahmapuram plant which is the authorized waste disposing unit in Kerala but this is not for drug waste. Hence, safe drug disposal and unethical disposal of medications have to be considered as a major topic of study. This study was initiated with an objective to come across the distributors and to examine the practices towards unused and expired medicines and their knowledge on safe disposal of medication. Since we don't possess a proper guideline towards medication disposal in our country, it has become a need to study the waste management area of pharmaceutical vicinity

AIM: 
The study was performed to check the knowledge and awareness regarding safe drug disposal methods among drug distributors with the hope that it could become a keystone in this area.

\section{OBJECTIVE:}

- To examine the knowledge and practices towards unused and expired medicines by pharmaceutical distributors.

- To provide a reference point for competent authorities in developing and implementing a take-back program for waste medicine.

- To understand the problems faced on medicine waste disposal among drug distributors

- To increase awareness and give encourage on safe and standard pharmaceutical waste

\section{METHODOLOGY}

\section{Study Area:}

The study was conducted in Ernakulum district in the southern state of Kerala. It is located in the central part of Kerala. Ernakulam district is home to over $12 \%$ of Kerala's population. The district includes the largest metropolitan region of the state. It is predominantly a commercial centre with numerous small, medium and large scale businesses. The state is rich in rivers and susceptible to flood, which can be contaminated by pharmaceutical waste products. The Periyar River, Kerala's longest, flows through almost all the taluks of Ernakulam. The average yearly rainfall in the district is $3432 \mathrm{~mm}$.

\section{Study Design and Data Collection:}

The population of the study comprised of drug distributors from various areas of Ernakulum district. The study was deported among pharmaceutical drug distributers in the period of October 2019 to January 2020. Drug distributors who gave their interest in the study were allowed to participate. A questionnaire survey and key informant interview were used for the study. The pretested revised and adapted questionnaires was prepared and given to the drug wholesalers at the time of visit. The participants were asked answer the questionnaire and also conducted face-toface interviews while filling up the questionnaires to get the exact details and truth behind the actual situation. In our study, information on the disposal of unused and expired drugs was difficult to obtain as it concerns what might be defended are unethical as it can lead hazards to environment. We assured the participants that all the information they provide will kept confidential.

The questionnaire was designed to collect all the available data about the sources of information regarding the knowledge, attitude and practice of drug distributors or wholesalers in connection with proper drug waste disposal. The questionnaire designed was first focussed on the demographic details of the participant like name of the distribution, name of the owner or manager 
who is participating in this survey, gender, qualification, their experience in that firm and the years of experience of their business in this field. In the next part, the participants are requested to point out their views and response to a series of statement about the awareness on drug waste management, their method of waste drug disposal, average amount of waste accumulated in premises per month, whether they have any drug waste disposal policy or method in their distribution centre organized by the drug distributors or drug wholesalers association and questions regarding the project 'Proud' started by the state government for drug disposal system, and their recommendations and challenges in drug waste management. During the course of the interview tape recorder were not used, only note-writing formats were used to collect data.

\section{Data Analysis:}

The questionnaire forms collected were sorted and examined for accuracy. The data were simplified and conversions were made wherever necessary. Percentages of responses were noted to make the study more communicative. Single and multiple responses were considered separately which made the study more enlightening.

\section{RESULTS AND DISCUSSION}

Distributors are intermediary companies that buy from manufacturers and sell to pharmacies, often additionally acting as warehouses for unwanted medications. Pharmacies return the expired, spilled and unused medicines to the same drug distributors from where they purchase the medicines. When we approached for our study we first introduced ourselves and described the objectives of our project.

We met around 45 distributors from Ernakulam district out of which 30 drug distributors were interested to participate. Most of them are in confused state whether to participate in the survey or not. Though we have taken steps to gain the trust of those we interviewed, there are some drug distributors who were uncomfortable for giving us the complete picture of their practices. We assured that all the answers would be kept confidential and the information gathered was only with an intension to improve the waste management system. This helped us to gain the trust of our interviews and increased willingness to share their views. The distributor said that they are facing many difficulties with the pharmaceutical waste. The distributors have to take all the expired medicines back refundable from the pharmacies and send back to respective manufacturer. But the problem arises when the manufacture wash the hands of it to take back the spilled and expired medications. After a year distributors had accumulated with pharmaceutical waste that should be returned to the manufacturers. 
Demographic details like name of the organization, place, and name of distributer and level of education of the person involved in this business were collected as our first step towards the study. The information collected helped us to know how long these distributors are practicing in this field. This gives us assistance to get a general idea of the distributer about medications and possibility of drug waste generated in their firm. Most of the distributors had more than 20 years of experience in this field and some of them had more than 50 years of experience.

Since the government and authorities doesn't ask for the presence of a registered pharmacist in the distribution center, none of the wholesalers had a registered pharmacist in their premises. Awareness about the drug waste management and the hazardous effects of the drug wastes were surveyed among the managers and among the most responsible staffs in the distribution center. $66.6 \%$ of the distributors were unaware about the drug waste management. Those who said, they have knowledge about the drug waste management were talking about waste cartons, and other packaging materials rather than the drug waste (Fig: 1).They speak about the irresponsibility of the authorities for collecting such wastes. This gives a whole picture that almost all the distributors participated in this study knows nothing about the drug waste management. During the Key Informant Interview (KII), it was found that most of the distributers don't have any idea on drug waste management and they treat the drugs as mere business commodities. The absence of a health care professional can be a major reason for the unawareness of the distributors on drug waste management. Periodic seminars and workshops can be helpful to overcome such situations.

Hardly any distributors told they were heard about the public issues going on the drug waste disposal as it is the current most discussed topic by the medical department but they don't even seen any guidelines laid by the government. It has become the need of the hour to lay down appropriate guidelines and reach them out to the different sectors of pharmaceutical industry.

75.67\% pharmaceutical waste generated in distribution center is by the expired dosage form that get back to the distributors from retail pharmacies and also from hospital pharmacies (Table: 1). $10.81 \%$ are non-reusable formulations and spilled pharmaceuticals respectively. Returns of rejected active pharmaceuticals were found to be rare. Most of them complain that the nonreusable and spilled formulations are not taken back by the manufacturers. But the distributers are pushed to collect them from the retailers so as to maintain a healthy business relation with the retailers, which have to be disposed along with municipal waste.

Table 1: Types of pharmaceutical waste retuned to wholesaler.

\begin{tabular}{ll}
\hline Pharmaceuticals Returned & \% Responded \\
\hline Expired dosage form & 75.67 \\
Non reusable formulations & 10.81 \\
\hline
\end{tabular}




\begin{tabular}{ll}
\hline Spilled pharmaceuticals & 10.81 \\
Rejected active pharmaceuticals & 2.70 \\
\hline
\end{tabular}

The quantities of expired and unused drug come back to the drug distributors were varied according to dealership of distributers. Most of them have a return collection in the range of 1050 kilograms per month (Table: 2). About 36.66\% of the distributors had below 10kg return collection of expiry and unused drug and $16.66 \%$ of distributors had drug waste between $10-20 \mathrm{~kg}$ and $33.33 \%$ had $20-50 \mathrm{~kg}$ of waste per month. Over $50 \mathrm{~kg}$ drug wastes are accumulated in each month among $10 \%$ of drug distributors. The methods for calculation of total drug waste per month in distribution center were discussed. Most of them uses computer based applications that are helpful in maintaining the records, return data, grouping drugs according to batch number and expiry date etc. some wholesalers don't have any methods for the calculation of total drug returned per month to their premises.

Table 02: Quantity of expiry and unused drug returned to distributors per month

\begin{tabular}{ll}
\hline Amount Of Return(per month) & \% Responded \\
\hline Below $10 \mathrm{~kg}$ & 36.66 \\
$10-20 \mathrm{~kg}$ & 16.66 \\
$20-50 \mathrm{~kg}$ & 33.33 \\
Over 50kg & 10 \\
\hline
\end{tabular}

As a continuation to the above noticed matters we put the question with a purpose to know what have been done with the medication that returned to the distribution center. $90 \%$ of the participants answered that they return them to the manufacturer and we found that it is impossible to return all the waste drugs to the manufacturer and "anyone who says otherwise is not being honest," which led us to seek the distributors how they achieved this (Figure: 2). Because to return all the drug waste accumulated to the manufacturer is of high cost for transportation both for the distributor and manufacturer. In Kerala we have only 3 or 4 drug manufacturers with less than 10 preparations and most of the drugs are coming from northern part of India and from abroad. A group of 6.66\% responded that they stock unused and expiry drugs within their premises because when they file the return of these drugs, the manufacturers themself tells to dispose by the distributors. And these distributors don't know where to dispose. $3.33 \%$ of the distributors told that the accumulated unwanted drugs were given to the corporation waste collectors. One distributor said that they reduce the price of the drugs as their expiration dates approaches in order to sell them faster. The wholesalers are unaware of the disposal methods rather than returning to the manufacturer. Some of them stock the returned goods within the premises and removed later on with the other waste products. Lack of proper knowledge and facilities are found to be a major threat to proper drug 
disposal. Drug disposal facilities can be introduced at unit levels, which can reduce the unsafe handling of unused or expired medication. Some of them asked for scientific disposal plants, which are the current need of pharmacy in our state.

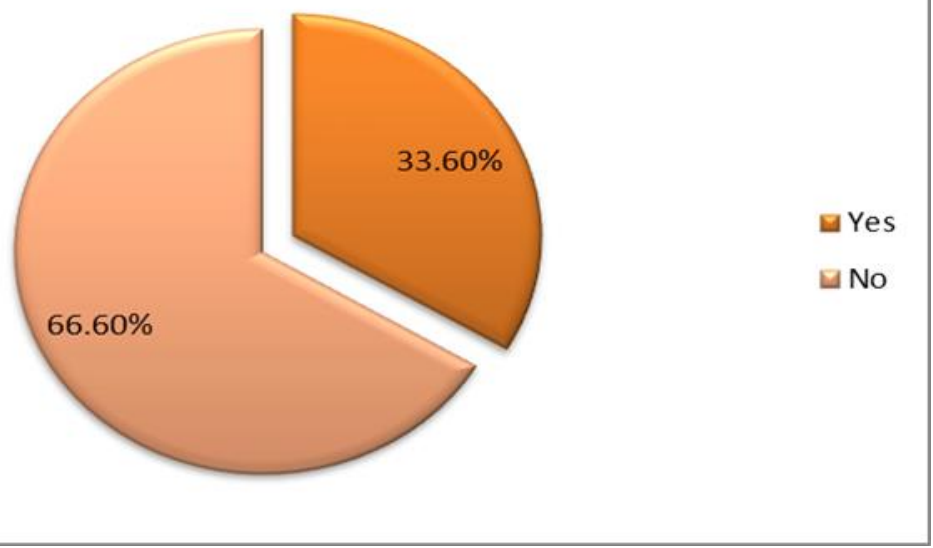

Figure 01: Awareness on drug waste management among distributors

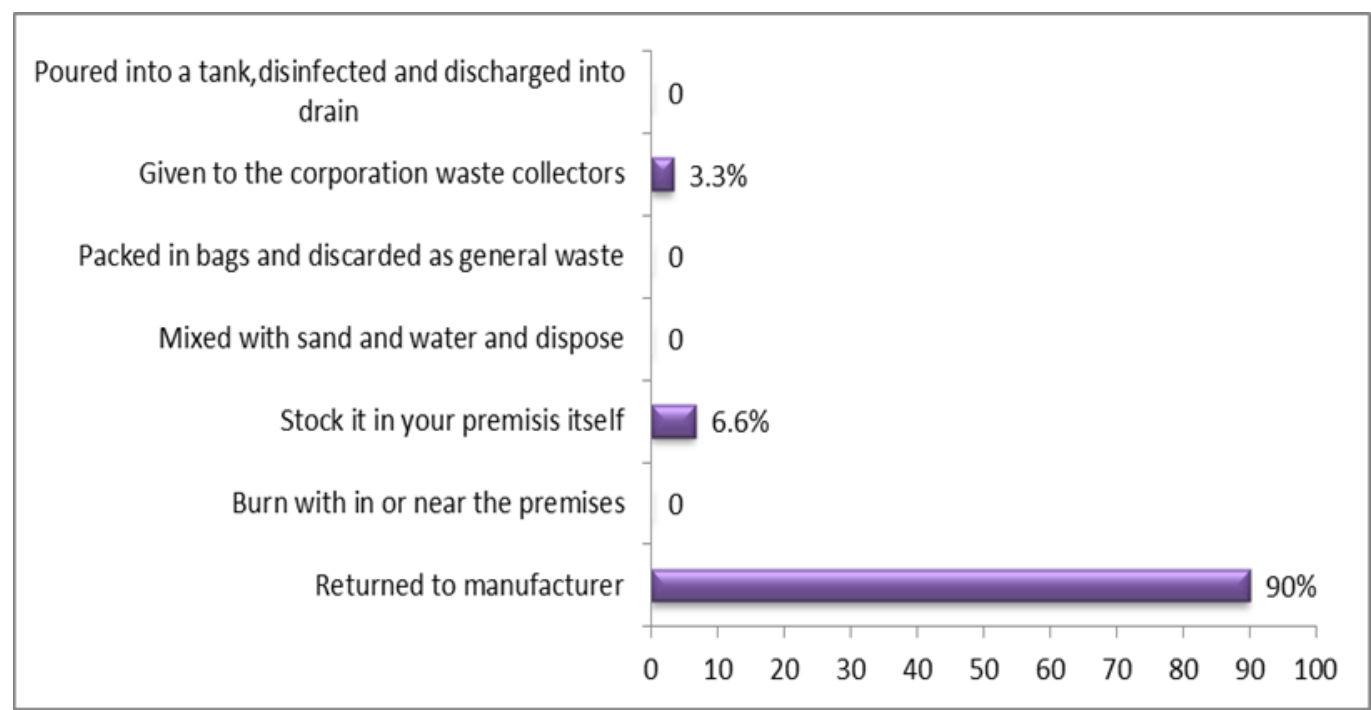

Figure 02: Disposal methods done with drugs returned to wholesalers

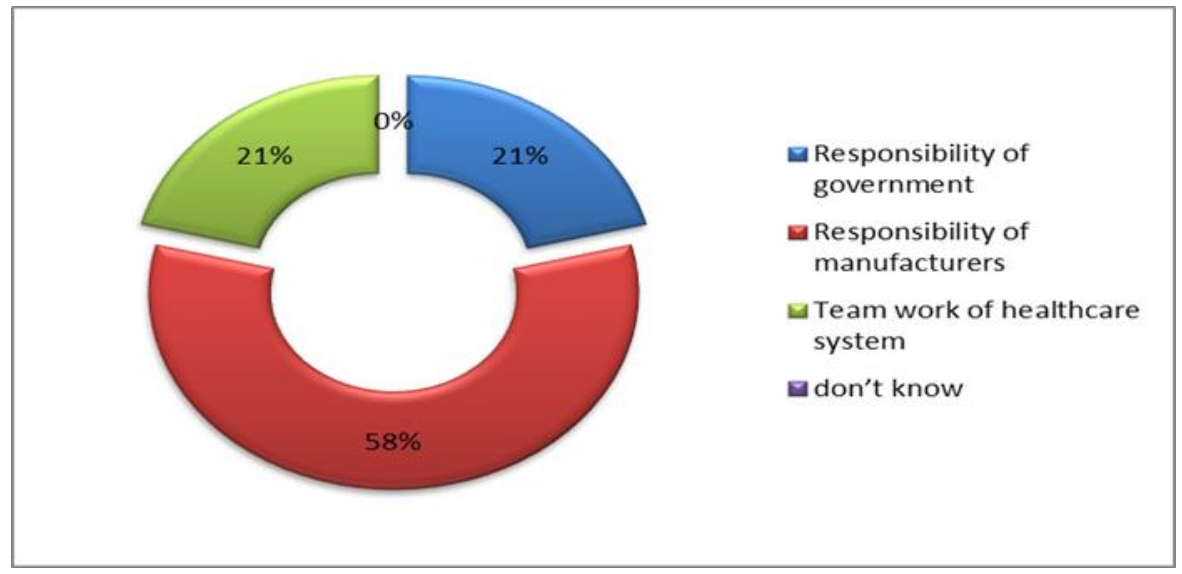

Figure 03: Responsibility of safe management of drug waste 
Distributers believe that it is the responsibility of manufacturers to collect and dispose them safely, but another group thinks that the conjoint effort of manufacturer, government and health care is required for the safe disposal of drug waste. The inspection by government authorities like drug inspectors is rare in the distribution center. There are no stringent guidelines on drug collection for manufacturers by the government as this happen to be the main reason for improper drug waste management (Figure:03).

The efficiency in collection of unused medications from wholesalers by the manufacturers was estimated. It was given prior importance in the survey because whenever pharmaceutical waste gets dumped in the premises or in the courtyards of the distribution center it will pollute the soil and water reservoirs if any. (Figure: 04) $90 \%$ of distributers gave a positive answer to this question but, there are cases when the manufacturers don't take back the unused medicines which get usually piled up in the distribution premises. This can discourage the distributer from collecting the unused ones from retailers thereby releasing them to the environment.

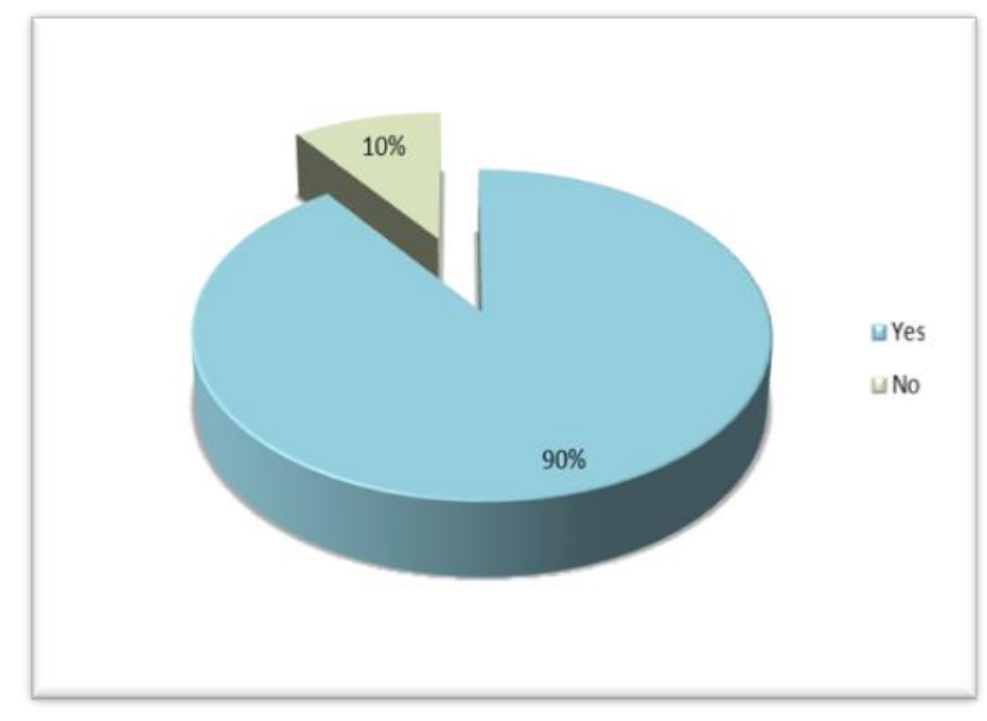

Figure 04: Collection of unused drugs by manufacturers.

On asking about the need of better disposal methods for waste medicine, the participants told that the current system of disposal practice is inadequate. Self-implementation of suitable system of waste disposal and regular collection of pharmaceuticals by the manufacturers from the distributers are to be made strict according to distributers.

Common challenges to proper disposal practice for drug waste were asked to the distributers. Poor education and awareness on management of drug waste disposal, poor documentaries of management of drug waste, poor law enforcement and low level of awareness on standard ways of disposal are found to be major threats to proper disposal (Fig:05). 


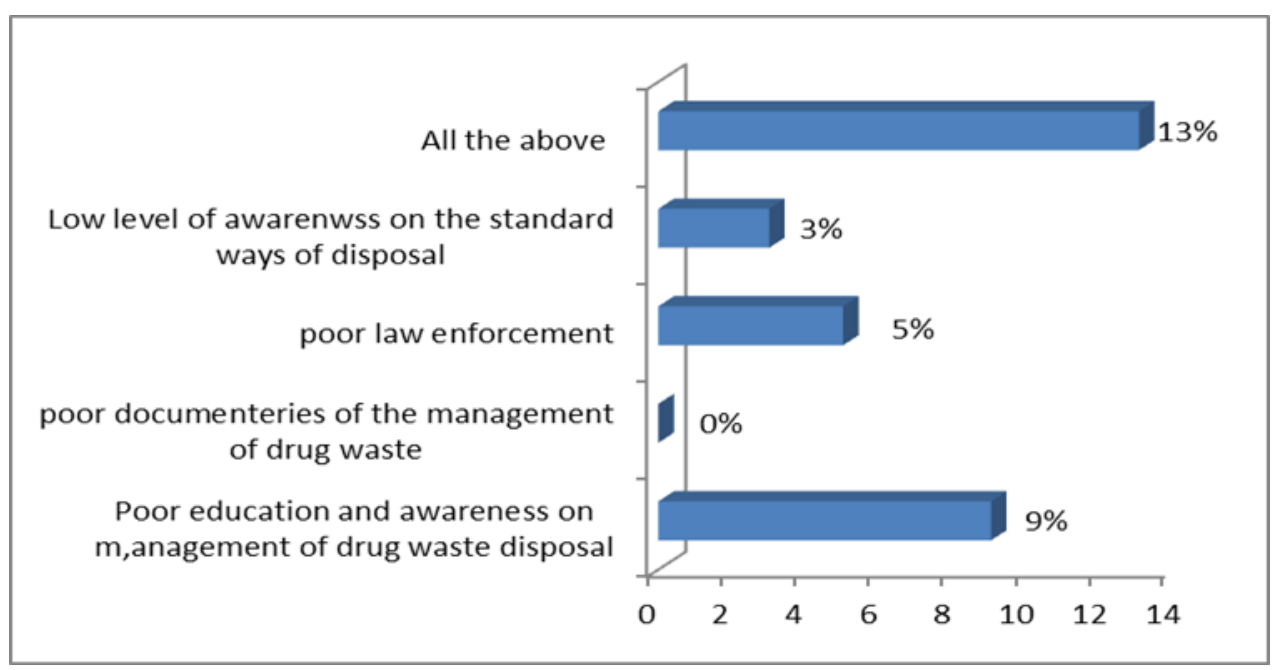

Figure 05: Challenges to proper disposal of drug waste

At last we check out the new venture PROUD project. Lot of them was unaware of the PROUD programme (Fig: 06). The project 'Programme for Removal of Unused Drugs' (PROUD) was implemented by the campaign titled PROUD is promoted jointly by State Drugs Control Department and All Kerala Chemists and Druggists Association (AKCDA) by which unused and expired medicines are collected in bins and disposed safely and scientifically. We educated those unaware persons about the ideas and objective of PROUD to our knowledge.

Awareness on "PROUD" project was provided to participants and conveyed valuable information on the topic. About five tons of expired and unused drugs collected from 200 collection boxes kept at the pharmacies and these collected waste were transported for scientific disposal center situated in Mangalore, Karnataka. It costs less than Rs.20 per $\mathrm{kg}$ of waste for disposal but the total expenditure including transportation costs was around 2 lakhs. Here it is the major problem found by the authorities as expenditure is high for transportation. Some of them passed on valuable information on IMAGE (Indian Medical Association Goes Ecofriendly), the biomedical waste treatment and disposal project of Indian Medical Association at Palakkad.

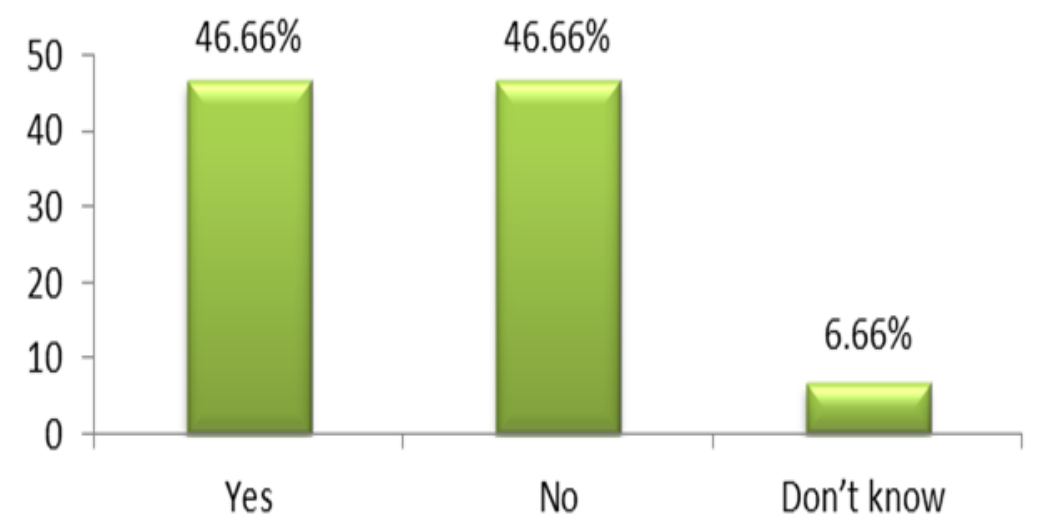

Figure 06: Aware on PROUD project 
Recommendations were requested to the distributers to revolutionize the current system of drug disposal. Creating public awareness on the ill effects and consequences of improper management of expired medicines was the opinion from majority (Fig: 07). Implementation of local government run disposal systems, adequate training of health workers and law enforcement were also recommended. The proper drug waste management can be achieved only when there is a conjoint participation of drug manufacturers, distributers, registered pharmacists and the common man.

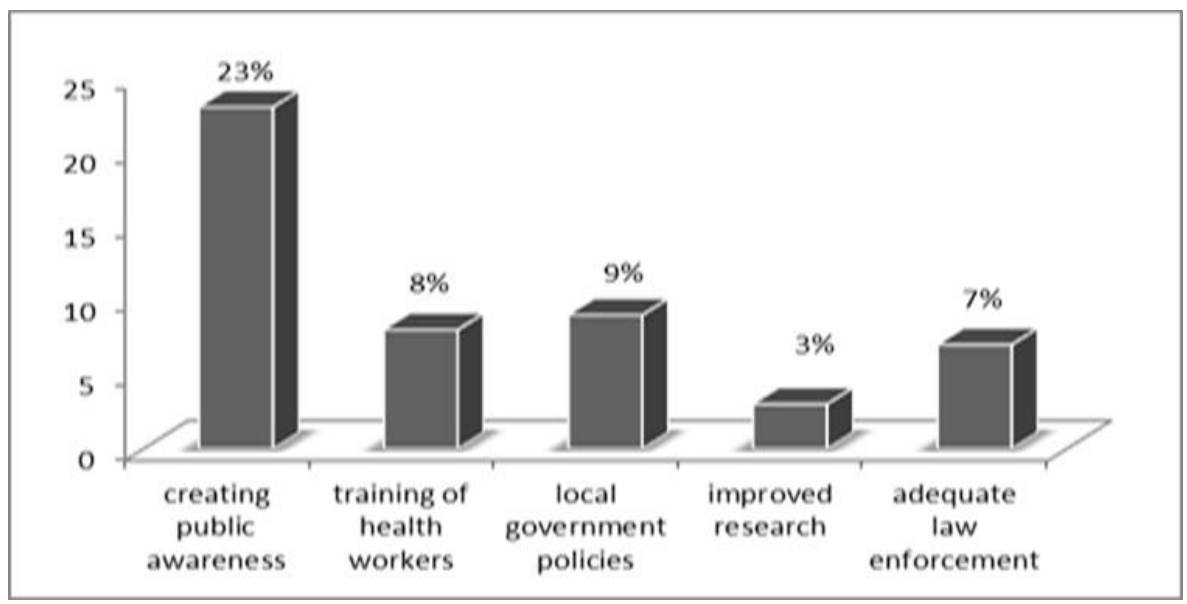

Figure 07: Recommendations to revolutionize current system of disposal

\section{CONCLUSION}

Drug distributers are handling the unwanted drugs in large quantity that are returning from the pharmacies. Since they do not possess any educational qualification on drugs, their use, or management, a close analysis should be done among drug distributers on drug waste management. It is common in the distribution centre the drugs get piled up for long period of time and dispose through the corporation waste part by part. Because apart from returning to manufactures they don't know what to do with these drugs, moreover this is business for them. Pharmaceutical products that are released in the environment affect the land and water resource of that area and also a threat to the human life. Absence of qualified professionals, less knowledge on drug waste management, poor legal framework is found to be major problems among drug distributers. Drug waste management programme like "PROUD"e should be encouraged to all sectors who are dealing with the drugs even the public. Established and applied laws along with community awareness will definitely make our aim easily possible. The expiry dates do not show that the medicine will lose its potency completely and will be no longer effective or become harmful after the expiry date. Mostly expiry date of a medicine is 1-5 years from the date of manufacturing if stored under perfect environment. Sometimes $90 \%$ of their potency retains after the expiry date. So the disposal of the expired and unused medicines is a key subject because it has direct effect on environment, 
on all life forms, including humans. In India, it is the peak time to conduct more studies and awareness programs regarding the disposal of medicines by manufacturers, distributors, pharmacies and also by the public. Otherwise the result of environmental consequences waiting for us is unpredictable.

\section{REFERENCES}

1. Muhammad Jaseem, Pramod Kumar, Remya Mariam John. An overview of waste management in pharmaceutical industry, The Pharma Innovation J 2017;6(3):158-161.

2. Ngwuluka et.al. An assessment of pharmaceutical waste management in some Nigerian pharmaceutical industries. African J Biotechnology 2011;10 (54): 11259- 11264,19.

3. Imad EMN, Asim AE, Tasneem JMS. (2017) Management of Post- Consumer Pharmaceutical Waste: An Overview. SOJ Pharm Pharm Sci, 4(5) 1-5.

4. Jelena Manoj lovic et.al. Pharmaceutical Waste Management in Pharmacies at the Primary Level of Health Care in Siberia-Situation Analysis. Indian Journal of Pharmaceutical Education and Research Vol. 49, Issue 2,Apr-Jun,2015.

5. Kusturica M P et.al. Storage and disposal of unused medications: Knowledge, behavior, and attitude among Serbian people. Int J Clin Pharm 2012;34: 604-10.

6. Atul Kadam, Shital kumar Patil, Sachin Patil, Anil Tumkur. Pharmaceutical Waste Management An Overview. Indian J Pharmacy Practice, Vol. 9, Issue 1, Jan- Mar, 2016.

7. Iweh Michael et.al. Assessment of disposal of expired and unused medications among community pharmacies in Anambra State southeast Nigeria: a mixed study design. Journal of Pharmaceutical Policy and Practice(2019)12:12

8. Charlotte L. Bekkar, Helga Gardardottir. Pharmacist's "Activities to reduce,MedicationWaste:AnInternationalSurvey.Pharmacy2018,6,94;doi:10.3390/pharma cy6030094,Survey.Pharmacy2018,6,94;doi:10.3390/pharmacy6030094.

9. Susi Kristina et.al. A Survey on Medicine Disposal Practice among Households in Yogyakarta. Asian Journal of Pharmaceutics, Jul-Sep 2018(Suppl).12(3).

10. Prachi Vasistha et.al. Questionnaire Method of Assessing Biomedical Waste in Shimla City- Case Studies of Public and Private Hospitals. Journal of Civil Engineering and Environmental Technology, Volume: 2,Issue16;October-December 2015.

11. JustynaRogowska.et.al. Pharmaceutical Household Waste Practice: Preliminary Findings from a Case Study in Poland. Environmental Management (2019)64;97-106.

12. Khansaa A. Ibrahim Albaroodi. Pharmacists ${ }^{\text {ee }}$ Knowledge Regarding Drug Disposal in Karbala.Pharmacy2019, 7, 57.

13. World Health Organization; International Pharmaceutical Association; International Solid 
Waste Association; UNICEF. Guidelines for Safe Disposal of Unwanted Pharmaceuticals in and after Emergencies; World Health Organization: Geneva, Switzerland, 1999.

14. Food Drug and Administration. Where and How to Dispose of Unused Medicines.2017 $09 / 10 / 2018$.

15. Daughton C G. Drugs and the Environment: Stewardship and sustainability. National Exposure research laboratory, Environmental Sciences Division, USEPA, Las Vegas, Nevada, report NERL-LV- ESD10/081,EPA/600//R-10/106 12 Sept 2010, 196pp.

16. Braund R, Peake MB, Shieffelbien L. Disposal practices for unused medications in New Zealand. Environment International 2009; 35(6): 952-5.

17. Patil, V.G., Pokhrel, K., "Biomedical solid waste management in an Indian hospital: a case study", Waste Management, 25, 2005,pp 592-599.

18. Yadav, M., “Hospital Waste - A major problem”. Hospital Today, 8, 4, 2001, pp 276-282.

19. Bashaar M, Thawani V, Hassali MA, Saleem F. Disposal practices of unused and expired pharmaceuticals among general public in Kabul. BMC Public Health 2017;17: 45.

20. Seehusen DA, Edwards J. Patient practices and beliefs concerning disposal of medications. The Journal of the American Board of Family Medicine. 2006; 19(6):542-7.

21. Jones OAH, Voulvoulis N, Lester JN. Human pharmaceuticals in the aquatic environment a review. Environ Technol. 2001; 22(12):1383-94.

22. Abrons J, Vadala T, Miller S, Cerulli J. Encouraging safe medication disposal through student pharmacist intervention. J American Pharmacists Association. 2010; 50 (2):16973.

23. Anup Jagarlamudi, Asma Begum, Mahalakshmi Teegala. A survey Based Study on the Assessment of Knowledge and Practice of Community Pharmacy Personal on Good Pharmacy Practice in Hyderabad. Indian J Pharmacy Practice 2(1): 2018.

24. Imad EMN, Asim AE, Tasneem JMS. (2017) Management of Post- Consumer Pharmaceutical Waste: An Overview. SOJ Pharm Pharm Sci, 4(5) 1-5.

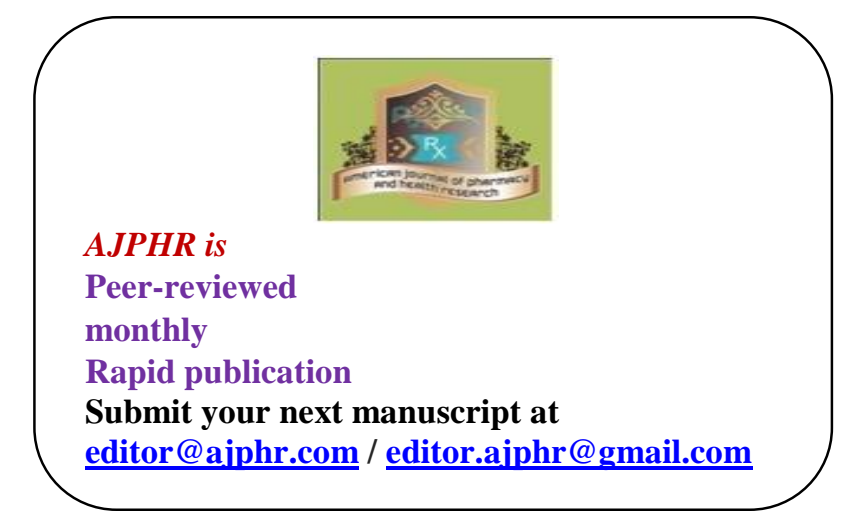

